\title{
INTELIGENCIA EMOCIONAL COMO ESTRATÉGIA DE PREVENÇÃO CONTRA A SINDROME DE BURNOUT
}

\author{
Clecilene Gomes CARVALHO ${ }^{1}$ \\ Sérgio Ricardo MAGALHÃES ${ }^{2}$
}

\begin{abstract}
${ }^{1}$ Enfermeira pela Universidade Vale do Rio Verde (Unincor), campus Betim. Especialização em Enfermagem do Trabalho. Pós-graduanda em psicologia multifocal. Pós graduanda em Saúde Pública com Ênfase em Saúde da Família. Complementação pedagógica em ciências biológicas. Membro da Associação Mineira de Hipertensão Pulmonar AMIHAP. E-mail: clecilene@globo.com

${ }^{2}$ Doutor em Engenharia Biomédica, docente do curso Enfermagem da Universidade Vale do Rio Verde (UniCor), campus Betim. E-mail: sergio.magalhães@unincor.edu.br
\end{abstract}

Recebido em: 30/10/2013 - Aprovado em: 15/10/2013 - Disponibilizado em: 15/01/2014

Resumo: O trabalho é uma atividade que pode ocupar grande parcela do tempo de cada indivíduo e do seu convívio em sociedade, mas o trabalho nem sempre possibilita realização profissional. Pode, ao contrário, causar problemas desde insatisfação até exaustão. $\mathrm{Na}$ síndrome de burnout uma das principais manifestações é o esgotamento emocional/exaustão, além da redução da realização pessoal no trabalho e despersonalização do outro. O presente trabalho parte da premissa que as emoções definem a motivação, o entusiasmo e nossos gostos, sentidos e sonhos pela vida. Portanto o objetivo deste estudo de revisão bibliográfica propõe descrever a importância da inteligência emocional como forma de prevenir a Síndrome de Burnout.

Palavras chave: Síndrome de Burnout. Inteligência emocional. Prevenção. Saúde do Trabalhador.

\section{EMOTIONAL INTELLIGENCE AS A STRATEGY FOR PREVENTION AGAINST THE BURNOUT SYNDROME}

\begin{abstract}
Work is an activity that can occupy a large portion of time each individual and their life in society, but the work is not always possible professional achievement. It may instead cause problems since dissatisfaction until exhaustion. In the burnout syndrome is a major manifestation emotional depletion / exhaustion, and reduced personal accomplishment and depersonalization of the other. This paper assumes that emotions define the motivation, enthusiasm and our tastes, senses and dreams for life. Therefore the purpose of this literature review suggests describing the importance of emotional intelligence as a way to prevent burnout syndrome.
\end{abstract}

Keyworks: Burnout Syndrome. Emotional Intelligence. Prevention. Occupational Health.

\section{INTRODUÇÃO}

O trabalho é uma atividade que pode ocupar grande parcela do tempo de cada indivíduo e do seu convívio em sociedade. Dejours (1992) afirmava que o trabalho nem sempre possibilita realização profissional. Pode, ao contrário, causar problemas desde insatisfação até exaustão.
As transformações sociais, econômicas, organizacionais e jurídicas exercem profunda influência sobre o processo de saúde adoecimento e a qualidade de vida nos contextos laborais (BORGES et al, 2002; GALINDO et al, 2012).

Observa-se, no mundo, tendência crescente para abordar os aspectos negativos 
da experiência no trabalho, utilizando a perspectiva da síndrome de burnout.

Tradicionalmente, a síndrome de burnout tem sido definida como uma situação na qual a pessoa afetada experimenta sentimentos de cansaço emocional, despersonalização e falta de realização pessoal. A fadiga emocional impede os trabalhadores de exercer o seu trabalho devido a sua aparente falta de energia, que leva à falta de entusiasmo, frustração e tensão. A despersonalização refere-se ao desenvolvimento de sentimentos e comportamentos negativos para com outras pessoas e com o trabalho, e muitas vezes envolve culpar os outros pelos próprios problemas. Já a falta de realização se refere à tendência para avaliar a capacidade própria de uma forma negativa e envolve sentimentos de infelicidade e insatisfação, o que origina sentimentos de inadequação e fracasso (MARIN et al, 2011; GALINDO et al, 2012).

Embora burnout tenda a ser mais prevalentes em profissões de assistência ou serviço, tem sido observada em todos os tipos de ocupações.

Visto que na síndrome de burnout uma das principais manifestações é o esgotamento emocional/exaustão, além da redução da realização pessoal no trabalho e despersonalização do outro. $\mathrm{O}$ presente trabalho parte da premissa que as emoções definem a motivação, o entusiasmo e nossos gostos, sentidos e sonhos pela vida. Portanto o objetivo deste estudo de revisão bibliográfica propõe descrever a importância da inteligência emocional como forma de prevenir a síndrome de burnout.

\section{METODOLOGIA}

Trata-se de um trabalho de revisão bibliográfica do tipo descritivo. Para a realização do estudo foi utilizando a base de dados da La Literatura Latino Americana e do Caribe em Ciências da Saúde (Lilacs), Scientific Electronic Library Online (Scielo), National Library of Medicine (Medline), do Centro Latino Americano e do Caribe de Informação em Ciências da Saúde (BIREME.

Os objetivos serviram para classificar e estruturar a revisão bibliográfica. Uma vez classificada e estruturada, esta serviu de base para uma ampla análise do tema.

Foram utilizadas as seguintes palavras chaves: Síndrome de Burnout; Esgotamento profissional; Inteligência emocional; Prevenção; Saúde do Trabalhador. Para a definição dos descritores/palavras-chave foi utilizado o DeCs - descritores em ciência da saúde. Uma linguagem única na indexação de artigos de revistas científicas, livros, anais de congressos, relatórios técnicos, e outros tipos de materiais. Sua finalidade é facilitar a pesquisa e recuperação de assuntos da literatura científica nas fontes de informação 
disponíveis na Biblioteca Virtual em Saúde (BVS) como LILACS, MEDLINE e outras.

A busca foi feita para o período compreendido entre setembro a dezembro de 2012, foram selecionandos artigos publicados em língua portuguesa, inglesa e espanhola.

Faz-se necessário ressaltar que no banco de dados BVS quando associado às palavras chaves síndrome de burnout e inteligência emocional foram encontrados 05 artigos sendo apenas 01 completo. Já quando associamos a IE com esgotamento profissional foram encontrados 27 artigos, porem apenas 05 completos. A associação de síndrome de burnout e esgotamento profissional resultaram em 145 artigos completos. Para o descritor inteligência emocional foram encontrados 194 artigos completos e para síndrome de burnout 234 artigos completos, já o descritor esgotamento profissional foram encontrados 699 artigos completos.

Devido o grande número de artigos relacionados à síndrome de burnout e esgotamento profissional, levaram-se em consideração, para a escolha dos referenciais, os artigos mais recentes. Em relação à associação de inteligência emocional com síndrome de burnout e esgotamento profissional foram utilizados 04 artigos dentre os 05 disponíveis.
Após a seleção dos artigos, fez-se busca ativa entre as citações bibliográficas para identificar artigos de relevância que não tivessem aparecido no primeiro levantamento. Selecionaram-se artigos epidemiológicos, conceituais e de revisão que relacionassem o burnout, seus aspectos conceituais relacionados à inteligência emocional.

\section{RESULTADOS E DISCUSSÃO}

São muitos os artigos relacionados à síndrome de burnout, mas poucos os que relacionam a inteligência emocional como forma de preveni-lo.

Grazziano e Ferraz (2010), afirmam que no trabalho é importante, possuir condições materiais e emocionais necessárias para exercê-lo com autonomia e segurança, além do reconhecimento público pelo que se faz, estas são qualidades indispensáveis para garantir a motivação, compromisso e produtividade. $\mathrm{O}$ desafio mental estimula o profissional psicologicamente frente as tarefas a serem executadas. As pessoas se sentem mais estimuladas e motivadas em atividades que exijam o uso de suas habilidades mentais; se o feedback pelo seu desempenho for positivo, sua satisfação profissional é elevada. $\mathrm{Na}$ situação oposta, se a carga mental ultrapassar a competência do indivíduo, o sentimento de frustração e inadequação surge levando ao estresse.

É importante salientar que o estresse surge quando o indivíduo tem que enfrentar 
situações que exigem uma adaptação e podem ser interpretadas por ele como um desafio (GRAZZIANO; FERRAZ, 2010), como por exemplo, excitação emocional, esforço excessivo, fadiga, concentração, humilhação ou mesmo sucesso grande e inesperado, cujo efeito pode ser físico, mental e/ou somático (MIGUEL; NORONHA, 2009). interpretação e a emoção causada por estes acontecimentos iniciam uma série de eventos em nível bioquímico que levarão a descargas hormonais, mediadas pelo sistema nervoso autônomo, via sistema límbico e pelo sistema nervoso central, via hipotálamo, a fim de preparar o organismo a enfrentá-las e restabelecer o equilíbrio (homeostase) (GRAZZIANO; FERRAZ, 2010). Trata-se de um mecanismo adaptativo e fisiológico (MIGUEL; NORONHA, 2009).

Mas o problema acontece quando o estresse ultrapassa os níveis adaptativos e chega à fase de exaustão/cronicidade denominado de síndrome de burnout ou síndrome do esgotamento profissional, termo que designa um tipo de resposta prolongada a estressores emocionais e interpessoais crônicos no trabalho (BRASIL, 2001 pg.191; KITZEL; RODRIGUES, 2008 MIGUEL; NORONHA, 2009; GRAZZIANO; FERRAZ, 2010; VERARDI et al, 2012).

Sendo o trabalhador um ser biopsicossocial a análise do desenvolvimento da síndrome de burnout deve proceder através de um olhar holístico para reconhecer os diversos fatores de risco dos quais o trabalhador esta exposto.

Portanto para enumerá-los são levadas em consideração quatro dimensões: o indivíduo, a organização, sociedade e o trabalho, pois todos direta ou indiretamente sofrem com os efeitos da síndrome de burnout. Claro que a maneira como essas características se combinam entre si, podem vir a postergar ou facilitar o processo da Síndrome de Burnout (TRIGO et al, 2007).

Quando se fala a nível individual os pontos a serem considerados é a idade, sexo, nível educacional, nível de resiliência, motivação entre outros. Já em relação às características organizacionais o ambiente físico, as normas institucionais, a autonomia o nível de burocracia estão entre os fatores para o desenvolvimento da síndrome de burnout. Tratando-se da sociedade os fatores predisponentes são a cultura, o prestigio, o suporte familiar e social (CARVALHO; MAGALHÃES, 2011).

Os estressores do ambiente de trabalho podem ser categorizados em seis grupos: fatores intrínsecos para o trabalho (condições inadequadas de trabalho, turno de trabalho, carga horária, contribuições no pagamento, viagens, riscos, nova tecnologia e quantidade de trabalho), papéis estressores (papel ambíguo, papel conflituoso, grau de responsabilidade para com pessoas e coisas), relações no trabalho (relações difíceis com o chefe, colegas, subordinados, clientes sendo 
diretamente ou indiretamente associados), estressores na carreira (falta de desenvolvimento na carreira, insegurança no trabalho devido a reorganizações ou declínio da indústria), estrutura organizacional (estilos de gerenciamento, falta de participação, pobre comunicação), interface trabalho-casa (dificuldade em lidar/manejar com esta interface) (STACCIARINI; TRÓCCOLI, 2001).

De natureza multidimensional, a síndrome de burnout envolve três componentes básicos: 1) exaustão emocional, com sentimentos de extrema fadiga e percepção de incapacidade para "se doar" afetivamente; 2) despersonalização, com o desenvolvimento de atitudes cínicas e sentimentos negativos, uma reação imediata após a instalação do cansaço e 3) insatisfação com a própria realização profissional, com tendência a se avaliar negativamente, especialmente na relação com os usuários ou clientes, com sentimentos de infelicidade e insatisfação com as próprias realizações no trabalho (Maslach \& Jackson, 1981 apud BRASIL, 2001; VERARDI et al, 2012; MOREIRA et al, 2009).

O Esgotamento/exaustão tem origem em duas ocasiões: 1) Quando a situação à qual o indivíduo terá que se adaptar (estímulo externo ou interno) exigir intensa participação emocional e persistir continuadamente. Nesse caso há um esgotamento por falência adaptativa devido aos esforços (emocionais) para superar uma situação persistente. Isso quer dizer que o estímulo para o estresse seria ameaçador tanto para a pessoa que a ele reage, quanto para outras pessoas submetidas ao mesmo estímulo. 2) Quando a pessoa não dispõe de uma estabilidade emocional suficientemente adequada para adaptar-se a estímulos não tão traumáticos, objetivamente falando. Isso quer dizer que a pessoa sucumbiria emocionalmente às situações não tão agressivas a outras pessoas colocados na mesma situação, mas, não obstante, agressivas particularmente a ela (BALLONE, 2008).

O profissional afetado pela síndrome sente-se exausto, frequentemente está doente, sofre de insônia, úlcera, dores de cabeça, problemas relacionados à pressão sanguínea, tensão muscular e fadiga crônica. Do ponto de vista organizacional, a síndrome de burnout está altamente correlacionada com baixa moral dos trabalhadores, absenteísmo e rotatividade de pessoal, resultados organizacionais negativos e baixo nível de comprometimento com o trabalho (CARLOTTO, 2010).

No Brasil, o Decreto $\mathrm{n}^{\mathrm{o}} 3.048$, de 06 de maio de 1999, aprovou o Regulamento da Previdência Social e, em seu Anexo II, trata dos Agentes Patogênicos causadores de Doenças Profissionais (Ministério da Saúde, Portaria $\left.n^{\circ} 1339 / 1999\right)$. O item XII da tabela de Transtornos Mentais e do Comportamento Relacionados com o Trabalho (Grupo V da 
Classificação Internacional das Doenças CID-10) cita a "Sensação de Estar Acabado" ("Síndrome de Burnout”, "Síndrome do Esgotamento Profissional") como sinônimos do burnout, que, na CID-10, recebe o código Z73.0. Portando, trata a Síndrome de uma doença e como tal capaz de provocar danos à saúde do trabalhador e por isso deve receber por parte da equipe que cuida dos trabalhadores toda a atenção para preveni-la e dar suporte para o enfrentamento quando já instalada (CARVALHO; MAGALHÃES, 2011; TRIGO et al, 2007; VIEIRA et al, 2006; BRASIL, 1999).

Embora a síndrome de burnout tenda a ser mais prevalentes em profissões de assistência ou serviço, tem sido observada em todos os tipos de ocupações, visto que as exigências profissionais é parte inerente de todos os setores (BORGES et al, 2002; GALINDO et al, 2012).

\section{ENFRENTAMENTO}

Dada a proporção dos danos causados pela síndrome de burnout tanto para o individuo, organização e as pessoas que convivem com o profissional acometido é que estudos reconhecendo a importância das emoções como forma de lidar com o estresse e assim impedir danos ao trabalhador têm sido realizados.

As emoções definem a motivação, o entusiasmo e nossos gostos, sentidos e sonhos pela vida (MONIZ; PEREIRA, 2004).
A reação mental imediata que detecta o perigo ou ameaça é a emoção, seja ela imaginária ou real, conduzindo o indivíduo aos esforços adaptativos (BALLONE, 2008).

No início da década de 1990, Salovey e Mayer (1990) reuniram várias pesquisas realizadas sobre inteligência e emoção e propuseram o construto inteligência emocional. Tal construto diz respeito à capacidade de raciocinar com emoções, integrar emoções para facilitar o pensamento, entender as emoções e ser capaz de gerenciálas a fim de promover o crescimento, tanto emocional quanto intelectual (Mayer \& Salovey, 1999 apud MIGUEL; NORONHA, 2009; WENG et al, 2011).

Inteligência emocional se refere à capacidade do indivíduo de compreender e utilizar informações emocionais a seu favor (ORTIZ; BELTRÁN, 2011; Mayer, 2001 apud MIGUEL; NORONHA, 2009).

Ainda no que diz respeito à definição, quatro aspectos ou áreas da inteligência emocional foram estabelecidos: 1) percepção, avaliação e expressão da emoção: nível de precisão para identificar as emoções em si e nos outros; 2) emoção facilitando o ato de pensar: capacidade de gerar pensamentos com certo planejamento, considerando um número maior de perspectivas; 3) compreensão e análise de emoções: compreensão de emoções complexas e contraditórias como amor e ódio e também a transição entre emoções como 
raiva, ódio e culpa; 4) controle reflexivo de emoções para promover o crescimento emocional e intelectual: capacidade de avaliar e refletir conscientemente sobre o sentimento despertado (MUNIZ; PRIMI, 2007; MIGUEL; NORONHA; 2009).

Portanto, a IE é o equilíbrio das emoções e atitudes de um indivíduo, por meio do qual ele desenvolve seu autocontrole, sendo importante para o sucesso pessoal, social e profissional (HOFFMANN et al, 2010).

Esta proposta apresentada à comunidade científica pelo modelo de Mayer e Salovey de que o ser humano é capaz de crescer com o aprendizado e com a análise de seus conteúdos emocionais, definindo a IE como a capacidade do indivíduo monitorar os sentimentos e as emoções dos outros e os seus, de discriminá-los e de utilizar essa informação para guiar o próprio pensamento e as ações (GONZAGA, MONTEIRO, 2011), só ficou, realmente, conhecida após a publicação Goleman em 1995 em seu livro inteligência emocional (COBERO; MUNIZ, 2006; MUNIZ; MIGUEL, 2007). Goleman (2007) sugere que os indivíduos emocionalmente inteligentes demonstram excelência nas relações humanas, revelam elevadas capacidades de liderança e têm um bom desempenho no trabalho.

Depois vieram outras definições como a proposta por Cury no seu livro Inteligência Multifocal. Onde o autor coloca como sendo a mais importante exploração do homem a exploração de si mesmo, do seu mundo intrapsiquico a fim de conhecer e controlar suas emoções, pois o homem que não se interioriza dança a valsa da vida engessado intelectualmente (CURY, 2006).

Cury (2001), levando em consideração que a inteligência emocional dos indivíduos pode ser aumentada através do treino, alargando a amplitude de competências pessoais e sociais já manifestadas sugere que através da técnica do DCD (duvidar, criticar e determinar) seja possível através de treino e autopercepção efetivarem este crescimento.

Segundo o autor, devemos duvidar das ideias dramáticas que muitas vezes alimentamos; duvidar das circunstâncias, pensamentos e fatos que nos deixem deprimidos, tristes, magoados, ansiosos; duvidar de sentimentos de inferioridade. Duvidar da própria incapacidade de ser feliz. A partir daí, Criticar diariamente tais pensamentos, posturas e comportamentos. Com um detalhe: em nós mesmos, não nos outros; Criticar pensamentos negativos, ideias perturbadora, angústias, medos e inseguranças que surjam interiormente. E, por fim, determinar ser feliz, equilibrado, sereno, harmonioso consigo mesmo, tranquilo; conquistar o que mais ama e ser líder de si mesmo, em vez de deixar-se conduzir. Determinar reações e comportamentos altruístas, ideias e posturas positivas que lhe tragam alegria, bem-estar e equilíbrio emocional. A emoção aprecia uma ordem, mas domina pessoas passivas. 
Sendo assim, a prevenção da síndrome de burnout envolve a priori um fortalecimento da inteligência emocional e claro mudanças na cultura da organização do trabalho, estabelecimento de restrições à exploração do desempenho individual, diminuição da intensidade de trabalho, diminuição da competitividade, busca de metas coletivas que incluam o bem-estar de cada um. A prevenção desses agravos requer uma ação integrada, articulada entre os setores assistenciais e os de vigilância. É importante que o trabalhador seja cuidado por uma equipe multiprofissional, com abordagem interdisciplinar com visão holística/biopsicossocial, que dê conta tanto dos aspectos de suporte ao sofrimento psíquicognitivo do trabalhador quanto dos aspectos sociais e de intervenção nos ambientes de trabalho (BRASIL 2001, pag.193).

O enfrentamento (coping) é, portanto, uma resposta individual de adaptação a situações consideradas difíceis. Mudanças no estilo de vida ou problemas associados a emoções negativas requerem novo repertório de comportamentos. Esse novo repertório inclui as estratégias de enfrentamento utilizadas para lidar com as novas demandas, inclui uma inteligência emocional desenvolvida (TAYLOR \& STANTON, 2007 apud VERARDI et al, 2012)

Para Pereira (2008), uma estratégia de coping para evitar a síndrome de burnout é os profissionais conhecerem os seus limites e respeitá-los e permitir ao lazer (dançar, ouvir música, brincar com os filhos, viver em harmonia no trabalho e em casa, ter amigos); Ter um animal de estimação, para quem gosta; Ler um bom livro, ligar para um velho amigo, pescar, viajar, exercitar; Sair da rotina trabalho-trabalho: é preciso viver, namorar, amar, permitir-se ser amado, ter fé, esperança e esperançar; Realizar coisas que the dê prazer; O profissional deve estar em realização constante e intensa quanto a suas necessidades, e descartando coisas desnecessárias que não lhe façam bem. É preciso que o profissional se pergunte assuma seu papel como autor e protagonista da sua história.

É importante salientar que o coping pelo trabalhador não exclui o dever das organizações de intervir, pois é dever do empregador, previsto no art. 170, da constituição da Republica Federativa do Brasil, zelar para que haja um ambiente de trabalho sadio e respeitar o trabalhador na condição de pessoa humana (BRASIL, 1988).

\section{CONCLUSÃO}

A Síndrome de Burnout é prejudicial nas esferas individual, social e organizacional, porque afeta negativamente a qualidade de vida dos trabalhadores, familiares e diminui quantitativamente e qualitativamente a produção das organizações. 
Após a leitura do referencial teórico, conclui-se que a Síndrome de Burnout pode ser evitada, desde que a cultura da organização favoreça a execução de atividades preventivas do estresse crônico. Portanto conhecer e reconhecer as situações que desencadeiam o estresse ajuda a compreender melhor a finalidade dos recursos adaptativos utilizados em tais situações e possibilita os profissionais que cuidam da saúde do trabalhador a imbuir nestes mecanismos de enfrentamento a fim de evitar o esgotamento que leva a Síndrome de Burnout. Uma forma de enfrentamento é conhecer e aprender a lidar com as emoções tornando-a uma importante arma para enfrentar a Sindrome de Burnout.

Existe um consenso, entre os autores citados, que a Inteligência Emocional pode ser desenvolvida e refinada através da reflexão sobre a prática, que conduz à estimulação do crescimento pessoal e emocional. Por isto, sugerimos a todos os trabalhadores, independente de qual área atue que busquem identificar seus pontos fortes e pontos fracos em relação à Inteligência Emocional a fim de lidar positivamente com as emoções.

\section{REFERENCIAS}

BALLONE, Geraldo J.. Ansiedade, Esgotamento e Estresse. In. PsiqWeb, Internet, revisto em 2008. Disponível em: http://www.psiqweb.med.br/site/?area=NO/L erNoticia\&idNoticia $=66$.
BRASIL. Constituição Federativa do Brasil de 1988. Disponível em http://www.planalto.gov.br/ccivil_03/constitu icao/constitui\%C3\%A7ao.htm.

BRASIL. DECRETO n. ${ }^{\circ}$ 3.048, de 06 de Maio de 1999. Disponível em: http://www.receita.fazenda.gov.br/legislacao/ decretos/Ant2001/1999/decreto3048/ListaBG rupoVCID10.htm

BRASIL - Ministério da Saúde. Doenças relacionadas ao trabalho: manual de procedimentos para os serviços de saúde (Série A. Normas e Manuais Técnicos). Brasília, 2001. Disponível em: http://dtr2001.saude.gov.br/editora/produtos/li vros/pdf/02_0388_M1.pdf.

BRASIL. Ministério de Estado da Saúde PORTARIA $\mathbf{N}^{\circ}$ 1.339, de 18 de novembro de 1999. Disponível em:

http://dtr2004.saude.gov.br/susdeaz/legislacao larquivo/Portaria 1339 de 18 11 1999.pdf

BORGES, Livia Oliveira et al . A síndrome de burnout e os valores organizacionais: um estudo comparativo em hospitais universitários. Psicol. Reflex. Crit. , Porto Alegre, v. 15, n. 1, 2002. Disponível em: http://www.scielo.br/scielo.php?script=sci art text\&pid=S0102$\underline{79722002000100020 \& \operatorname{lng}=\text { pt\&nrm=iso }}$

CARLOTTO, Mary S.. A relação profissional-paciente e a sindrome de Burnout. Encontro Revista de Psicologia v. 12, n.17. Anhanguera Educacional S.A, São Paulo, 2010. Disponível em: http://sare.unianhanguera.edu.br/index.php/re ncp/article/viewPDFInterstitial/784/849.

CARVALHO, Clecilene G.; MAGALHÃES, Sérgio R.. Síndrome de Burnout e suas consequências nos profissionais de enfermagem. Revista da Universidade Vale do Rio Verde, v. 9, n. 1, p. 200-210, Três Corações, 2011. Disponível em: http://revistas.unincor.br/index.php/revistauni ncor/article/view/86 
COBERO, Cláudia; Primi, Ricardo; MUNIZ, Monalisa. Inteligência emocional e desempenho no Trabalho: Um Estudo com MSCEIT, BPR-5 e 16PF. Paidéia (Ribeirão Preto), Ribeirão Preto, v 16, n. 35, dezembro 2006. Disponível a partir do

$<$ http://www.scielo.br/scielo.php?script=sci_a rttext\&pid=S0103$863 X 2006000300005 \& \operatorname{lng}=e n \& n r m=i s o>$.

Acesso em 26 de outubro de 2012. http://dx.doi.org/10.1590/S0103$\underline{863 \times 2006000300005}$

CURY, Augusto. Inteligência Multifocal. Cultrix: São Paulo, 2006.

CURY, Augusto. Treinando a emoção para ser feliz: nunca a autoestima foi tão cultivada no solo da vida. São Paulo: Editora Planeta do Brasil, 2001, p. 26-28, 38-41, 146. Disponível em:

http://www.docstoc.com/docs/1045752/Augu sto-Cury-Treinando-a-

Emo\%C3\%A7\%C3\%A3o-para-Ser-Feliz.

Acesso em 08 de novembro de 2012.

DEJOURS, C. Abdoucheli, E. Desejo ou motivação? A interrogação psicanalítica sobre o trabalho. In: DEJOURS, C.; ABDOUCHELI, E. \& JAYET, C.

Psicodinâmica do trabalho: contribuições da escola dejouriana à análise da relação prazer, sofrimento e trabalho. São Paulo: Atlas, 1994.

HOFFMANN, Michael et al. The impact of stroke on emotional intelligence. BMC Neurol, Florida, 2010; n. 103, vol. 10. Disponível em: http://www.ncbi.nlm.nih.gov/pmc/articles/PM C2987854/?tool=pubmed. doi: $10.1186 / 1471-$ 2377-10-103.

GALINDO, Renata Hirschle et al. Síndrome de Burnout Entre Enfermeiros de hum Hospital Geral da Cidade do Recife. Rev. esc. enferm. USP, São Paulo, v 46, n. 2, abril de 2012. Disponível em: http://www.scielo.br/scielo.php?pid=S0080$62342012000200021 \&$ script=sci_abstract $\&$ tl ng=pt. Acesso em 26 de outubro de 2012.
GOLEMAN, Daniel, ph.D. A inteligência emocional: a teoria revolucionaria que define o que é ser inteligente. Rio de Janeiro - Ed. Objetiva, $10^{\circ} \mathrm{ed}, 2007$.

GONZAGA, Alessandra Rodrigues;

MONTEIRO, Janine Kieling. Inteligência

Emocional no Brasil:. Hum panorama da

Pesquisa Científica Psic:. Teor. e Pesq. ,

Brasília, v. 27, n. 2, junho de 2011.

Disponível a partir de

$<$ http://www.scielo.br/scielo.php?script=sci_a rttext\&pid=S0102-

$37722011000200013 \& \operatorname{lng}=\mathrm{en} \& \mathrm{nrm}=\mathrm{iso}>$.

Acesso em 17 de outubro de 2012.

http://dx.doi.org/10.1590/S0102-

37722011000200013

GRAZZIANO, ES; FERRAZ, BIANCHI, ER. Impacto del estrés ocupacional y burnout en enfermeros. Enfermería Global - Revista eletrônica de enfermagem, $n^{\circ} 18,2010$.

Disponível em:

http://scielo.isciii.es/pdf/eg/n18/pt_revision1. pdf.

KITZEL, Stephanie; RODRIGUES, Andrea

B.. Burnout em Oncologia: um estudo com profissionais de Enfermagem. Einstein. 2008; 6(2):128-33. Disponível em:

http://apps.einstein.br/revista/arquivos/PDF/5

91-Einstein\%20v6n2\%20p128-33.pdf

MARIN, Jesus Monteiro et al. Burnout syndrome among dental students: a short version of the"Burnout Clinical Subtype Questionnaire" adapted for students (BCSQ12-SS). BMC Med Educ. vol. 11, 2011. Disponivel em: http://www.ncbi.nlm.nih.gov/pmc/articles/P MC3273439/?tool=pubmed

MIGUEL, Fabiano Koich; NORONHA, Ana Paula Porto. Estudo da relação entre inteligência emocional e estresse em ambientes de trabalho. Aval. psicol., Porto Alegre, v. 8, n. 2, ago. 2009 . Disponível em $<$ http://pepsic.bvsalud.org/scielo.php?script=s ci_arttext\&pid=S1677-

04712009000200008\&lng=pt\&nrm=iso $>$.

Acessos em 06 nov. 2012. 
MOREIRA, Davi de Souza et al .

Prevalência da síndrome de burnout em trabalhadores de enfermagem de um hospital de grande porte da Região Sul do Brasil. Cad. Saúde Pública, Rio de Janeiro, v. 25, n. 7, jul. 2009. Disponível em http://www.scielo.br/scielo.php?script=sci_art text\&pid=S0102$\underline{311 X 2009000700014 \& \operatorname{lng}=p t}$.

MUNIZ, Monalisa; PRIMI, Ricardo. Inteligência emocional e desempenho em policiais militares: validade de critério do MSCEIT. Aletheia, Canoas, n. 25, jun. 2007. Disponível em $<$ http://pepsic.bvsalud.org/scielo.php?script=s ci_arttext\&pid=S141303942007000100006\&lng=pt\&nrm=iso $>$. Acessos em 06 nov. 2012.

MONIZ; Marcela A.; PEREIRA, Rodrigo L.. As emoções como principais respostas mentais ao estresse. COFEN, anais do $7^{\circ}$ CBCENF, Fortaleza, 2004. Disponível em: http://189.75.118.67/CBCENF/sistemainscric oes/anais.php? evt $=4 \& \mathrm{sec}=28 \&$ niv $=4 \& \bmod =1$ $\& \mathrm{con}=85 \& \mathrm{pdf}=1$

ORTIZ, R.A.,BELTRÁN, B.E.J..

Inteligencia emocional percibida y desgaste laboral en médicos internos de pregrado. Educ Med 2011; v.14, nº1, pag. 49-55.

Disponível em:

http://scielo.isciii.es/pdf/edu/v14n1/original4. pdf. Acesso em 08 de novembro de 2012.

PEREIRA, Ana Maria T. B.. Burnout: Quando o trabalho ameaça o bem estar do trabalhador. São Paulo: Casa do Psicólogo, 2008 - Impressão do Brasil, $3^{\circ}$ edição. http://www.prt18.mpt.gov.br/eventos/2004/sa ude mental/anais/artigos/2.pdf

STACCIARINI, Jeanne Marie R.; TRÓCCOLI, Bartholomeu T.. O estresse ocupacional nd atividade DO Enfermeiro.
Rev. Latino-Am. Enfermagem de Ribeirão Preto, v 9, n. 2, abril de 2001. Disponível a partir do <http://www.scielo.br/scielo.php?script=sci_a rttext\&pid=S0104$11692001000200003 \& \operatorname{lng}=e n \& n r m=i s o>$. Acesso em 07 de novembro de 2012. http://dx.doi.org/10.1590/S010411692001000200003.

TRIGO, Telma R. et al. . Síndrome de burnout ou estafa profissional e os transtornos psiquiátricos. Rev. Psiq. Clín V.34, n.5; pag. 223-233. São Paulo, 2007. Disponível em:

http://www.honet.usp.br/ipq/revista/vol34/n5/ 223.html.

VERARDI, Carlos Eduardo Lopes et al. Esporte, burnout e estresse. Estud. psicol. (Campinas), Campinas, v 29, n. 3, setembro 2012. Disponível a partir do $<$ http://www.scielo.br/scielo.php?script=sci_a rttext\&pid=S0103166X2012000300001\&lng=en\&nrm=iso > . acesso em 06 de novembro de 2012. http://dx.doi.org/10.1590/S0103166X2012000300001.

VIEIRA, Isabela et al . Burnout na clínica psiquiátrica: relato de um caso. Rev. psiquiatr. Rio Gd. Sul, Porto Alegre, v. 28, n. 3, dez. 2006. Disponível em $<$ http://www.scielo.br/scielo.php?script=sci_a rttext\&pid=S0101-

$81082006000300015 \& \operatorname{lng}=$ pt\&nrm=iso $>$.

WENG, HC et al. Associations between emotional intelligence and doctor burnout, job satisfaction and patient satisfaction. Medical Education $n^{\circ} 45$, pag. 835-842, 2011. doi:10.1111/j.1365-2923.2011.03985.x Disponivel em: http://onlinelibrary.wiley.com/doi/10.1111/j.1 365-2923.2011.03985.x/pdf 